\title{
Effect of Internal Strain on Martensitic Transformations in NiTi Shape Memory Alloys
}

\author{
Danuta Stroz and Dariusz Chrobak
}

Institute of Materials Science, University of Silesia, Bankowa 12, 40-007 Katowice, Poland

\begin{abstract}
The analysis of the influence of precipitation processes as well as dislocation structure on the transformation course and its characteristic parameters in NiTi shape memory alloys was carried out. In order to describe structural changes caused by thermo-mechanical treatment, transmission electron microscopy technique was applied; the study included in situ observations during cooling and heating the specimen in the microscope. The structural changes were related to the evolution of the martensitic transformation determined from the differential scanning calorimetry (DSC) measurements. It was found that the non-homogeneity of stress fields caused by presence of coherent precipitates or by specific dislocation structure results in a multi-stage martensitic transformation. The transformation is preceded by the R-phase transition. Also this transformation can occur in many stages. A thermodynamical model of the multi-stage martensitic transformations occurring in the twocomponent NiTi alloys was elaborated, which allows anticipation of the transformation sequences in these alloys.
\end{abstract} [doi:10.2320/matertrans.MB201012]

(Received August 27, 2010; Accepted January 6, 2011; Published February 16, 2011)

Keywords: nickel titanium shape memory alloys, multi-stage martensitic transformation

\section{Introduction}

In the Ni-Ti system it is the B2 intermetallic NiTi phase that undergoes the reversible martensitic transformation to the B19' monoclinic phase. For an alloy of any composition (provided it ensures the B2 phase presence) cooled down very slowly the transformation occurs always at the same temperature i.e. about $300 \mathrm{~K}$. In the $\mathrm{Ni}$-rich alloys the precipitation process may take place that changes the transformation characteristic temperatures and/or its sequence. There are several variants of this process depending on the ageing temperature, $T_{\mathrm{a}} \cdot{ }^{1)}$ These are:

$$
\begin{aligned}
& \mathrm{B} 2_{0} \rightarrow \mathrm{B} 2_{1}+\mathrm{Ni}_{4} \mathrm{Ti}_{3} \rightarrow \mathrm{B} 2_{2}+\mathrm{Ti}_{2} \mathrm{Ni}_{3} \rightarrow \mathrm{B} 2_{3}+\mathrm{Ti} \mathrm{Ni}_{3}, \\
& T_{\mathrm{a}}<953 \mathrm{~K} \pm 10 \mathrm{~K} \\
& \mathrm{~B} 2_{0} \rightarrow \mathrm{B} 2_{1}+\mathrm{Ni}_{3} \mathrm{Ti}_{2} \rightarrow \mathrm{B} 2_{2}+\mathrm{Ti} \mathrm{Ni}_{3}, \\
& \quad 953 \mathrm{~K} \pm 10 \mathrm{~K}<T_{\mathrm{a}}<823 \mathrm{~K} \pm 10 \mathrm{~K} \\
& \mathrm{~B} 2_{0} \rightarrow \mathrm{B} 2_{1}+\mathrm{Ni}_{3} \mathrm{Ti} \text { for } T_{\mathrm{a}}>823 \mathrm{~K} \pm 10 \mathrm{~K},
\end{aligned}
$$

where $\mathrm{B} 2_{n, n=0,1,2,3}$ means supersaturated solid solution of $\mathrm{Ni}$ in the B2 phase of different Ni concentration.

However, the only particles that significantly influence the course of the martensitic transformation in the NiTi alloy are the $\mathrm{Ni}_{4} \mathrm{Ti}_{3}$ particles. The strain fields around these coherent precipitates as well as the decrease of the Ni concentration in the matrix change the characteristic transformation temperatures and cause occurrence of the R-phase transition preceding the B19' martensite formation. Similar effects take place in the NiTi equiatomic alloys deformed and then annealed at temperatures below the recrystallisation temperature. $^{2,3)}$ In both cases additional effects in form of a multistage transformation were often observed. The first data on the multistage martensitic transformation were given by Todoroki and Tamura, ${ }^{4)}$ Stróż et al. ${ }^{5)}$ and Zhu et al. ${ }^{6)}$ It was found that depending on the applied thermal treatment there exist three or even four more or less overlapping peaks on the DSC cooling curves. ${ }^{6}$ ) The occurrence of the R-phase transition in these alloys is understandable as this transition causes less lattice distortions and thus is favored when the internal stresses exist in the sample. However, the presence of two stages of the $\mathrm{R} \rightarrow \mathrm{B} 19^{\prime}$ transformation is still a matter of discussion.

In the paper the trial of explaining the above described transformation behavior is undertaken on the base of thermodynamical considerations.

\section{Experimental}

Commercial NiTi alloys of nominal composition Ni51 at $\%$-Ti and Ni50 at\%-Ti were the subject of the studies. The samples were homogenized at $1123 \mathrm{~K}$ for $3.6 \mathrm{ks}$ in order to ensure single phase material of the $\mathrm{B} 2$ structure.

The specimens of the Ni-rich alloy were aged in the temperature range $573-873 \mathrm{~K}$ for $3600 \mathrm{~s}$. The second alloy was cold rolled with the reduction of $10 \%$ and then annealed in the temperature range $573 \mathrm{~K}-873 \mathrm{~K}$. The alloy structure was studied with the use of the JEOL 3010 TEM operating at $300 \mathrm{kV}$ and the transformation course was observed with the use of the DSC technique (Perkin Elmer equipment) using the cooling/heating rate of 10 degrees/min.

\section{Results}

Directly after homogenization both alloys showed the ordered B2 structure with very small number of dislocations (Fig. 1). The DSC curves proved that a single transformation B2 $\leftrightarrow$ B19' below room temperature took place in the alloys (Fig. 2). The Ni-rich alloy showed quite a wide transformation range and low transformation characteristic temperatures which was due to large amount of $\mathrm{Ni}$ atoms in the solid solution. Ageing of the Ni-rich alloy in the temperature range $573-773 \mathrm{~K}$ causes precipitation of the $\mathrm{Ni}_{4} \mathrm{Ti}_{3}$ phase. The particles are of lenticular shape, form on the $\{111\}_{\mathrm{B} 2}$ habit plane and, dependent on the aging conditions, are coherent or semicoherent with the parent phase matrix. They produce large strain fields in the matrix lattice especially in the 

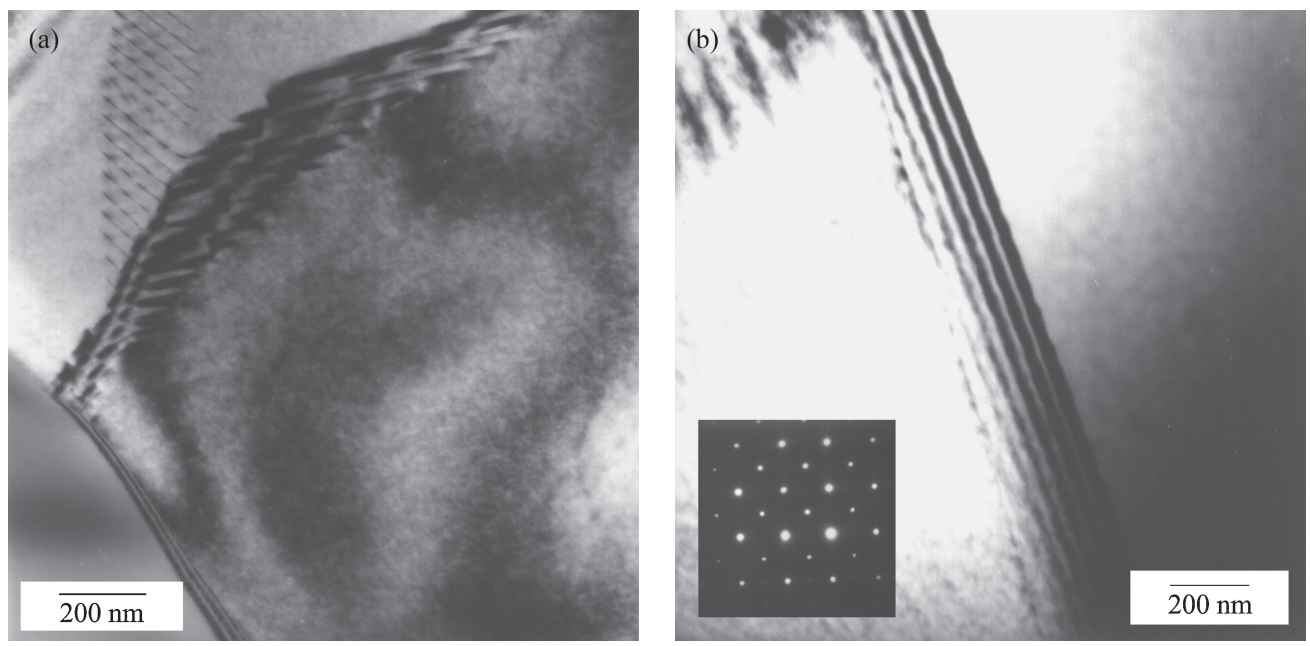

Fig. 1 Structure of the NiTi alloys homogenized at $850^{\circ} \mathrm{C} / 1 \mathrm{~h}$, (a) Ni51 at $\%$-Ti, (b) Ni50 at $\%$-Ti.
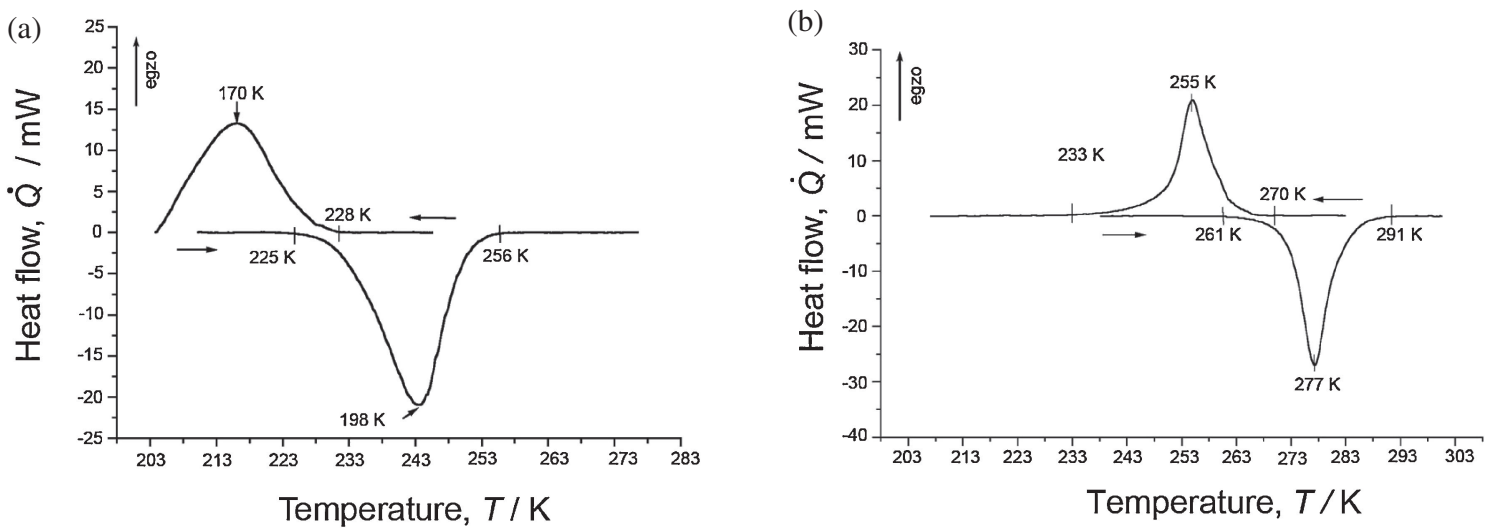

Fig. 2 DSC curves for the homogenized alloys (a) Ni51 at\%-Ti, (b) Ni50 at\%-Ti.
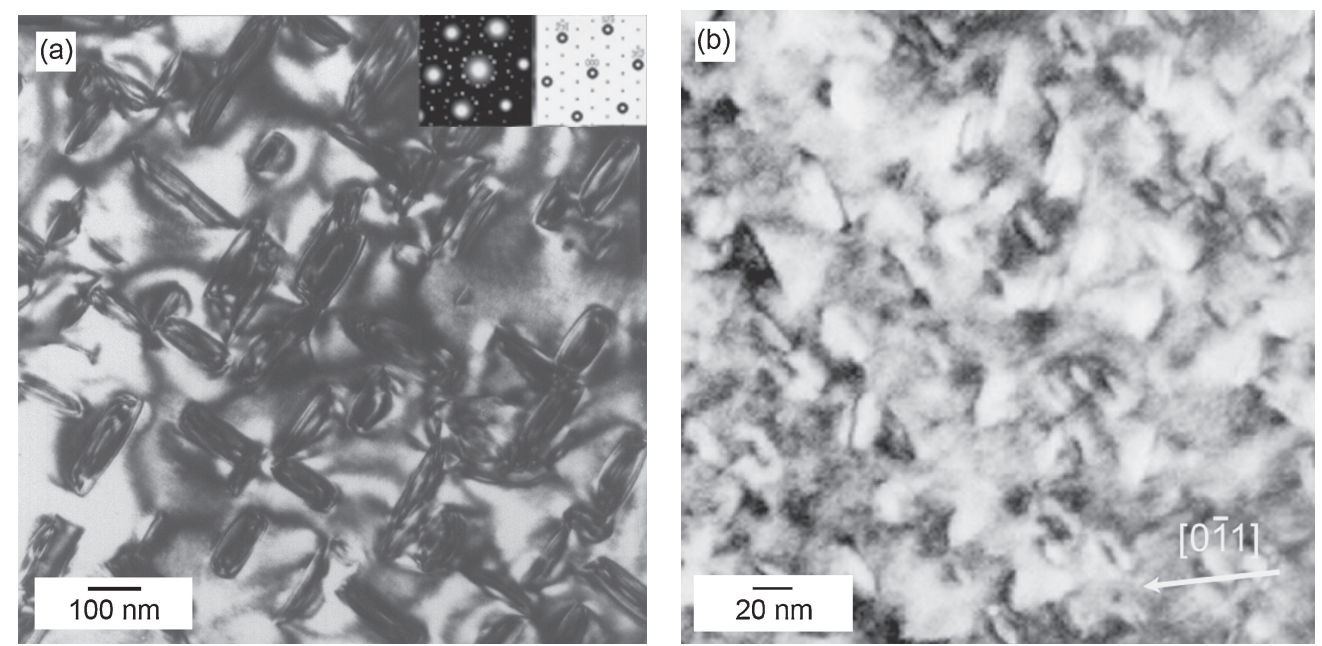

Fig. $3 \mathrm{Ni}_{4} \mathrm{Ti}_{3}$ precipitates in $\mathrm{Ni} 51$ at\%-Ti alloy aged at $723 \mathrm{~K} / 3.6 \mathrm{ks}$ (a) bright field image, (b) dark-field image in two-beam condition showing the strain fields around precipitates.

direction perpendicular to the particle i.e. $\langle 111\rangle$ direction of the B2 phase (Fig. 3). These strain fields are especially well seen in the dark field images taken in the two-beam conditions (Fig. 3(b)). The high resolution observation revealed coherency between the matrix and precipitate lattices
(Fig. 4). The inserted processed parts of the images reveal the lattice planes continuing through the interfaces, only some misfit dislocations can be distinguished in some places.

The DSC curves for the aged alloy showed a complicated character. ${ }^{7)}$ For short ageing times and/or low ageing 

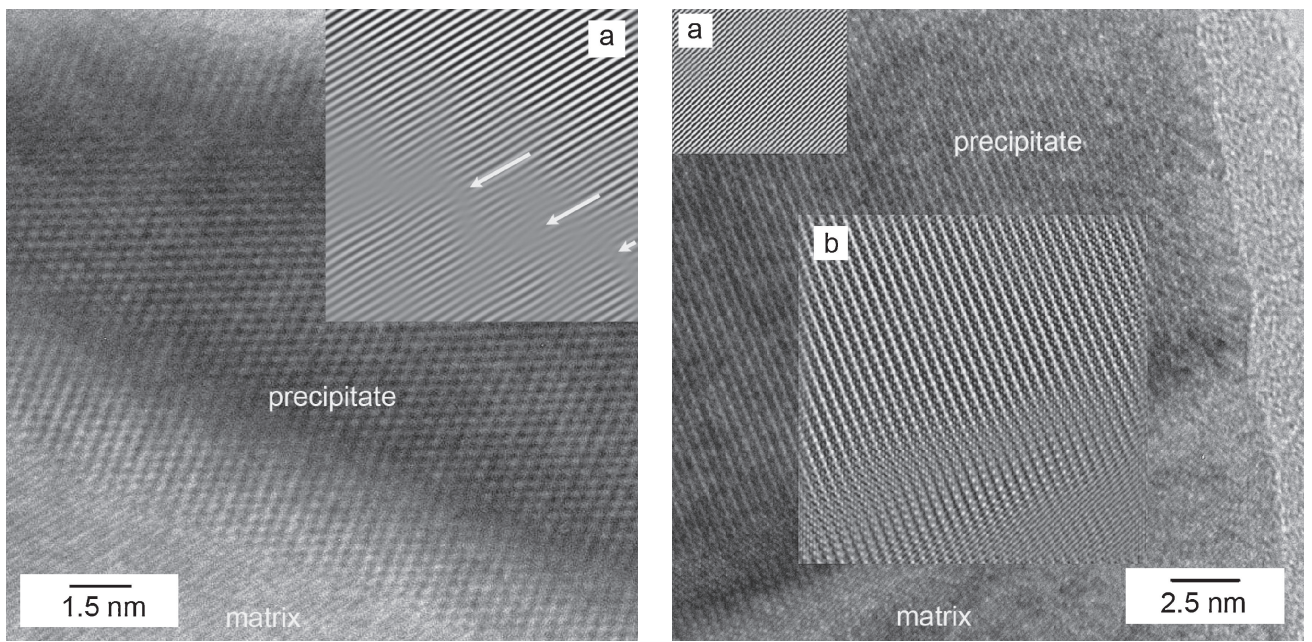

Fig. 4 High resolution images of the $\mathrm{Ni}_{4} \mathrm{Ti}_{3}$ precipitates coherent with the $\mathrm{B} 2$ matrix. Inserted filtered areas show continuity of the lattice planes (arrows indicate misfit dislocations) through the interface. The letter "a" indicates areas filtered with the use of the B2 matrix spots, the letter "b" indicates the area filtered with the $\mathrm{Ni}_{4} \mathrm{Ti}_{3}$ spots.

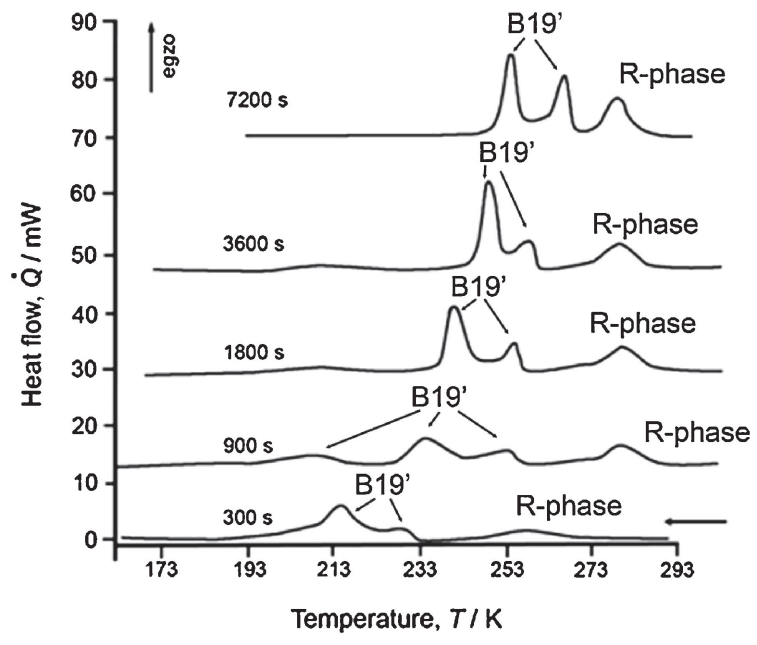

Fig. 5 DSC curves on cooling for the Ni51 at\%-Ti alloy aged at $773 \mathrm{~K}$ for different times.

temperature wide peaks for both transformations are observed, in some cases spread for two stages. Prolonging the ageing time causes occurrence of the two steps of the B19' transformation peaks. An example of the DSC cooling curves for the specimens aged at $773 \mathrm{~K}$ for different times is given in Fig. 5. Short ageing times cause that the peaks of both transformations are spread over a relatively large temperature range. Ageing at $773 \mathrm{~K}$ for longer times causes that the Rphase transition undergoes in a single step and the B $19^{\prime}$ phase is formed in two steps. In order to explain this complicated course of the transformations the observations during in-situ cooling of the sample in the TEM were carried out. It was found that on cooling the R-phase transformation takes place around the coherent particles at first (Fig. 6(b)) then at lower temperature in the regions between the precipitates (Fig. 6(c)) and the B19' transformations proceeds in the same way, first around the precipitates (Fig. 6(c)).

Very similar effects were observed in the near-equiatomic alloy subjected to cold-rolling followed by annealing. The DSC curves for the alloy showed multi-step transformations of both the R-phase and the B19' martensite (Fig. 7). The TEM observation revealed cellular structure of dislocations formed in the annealed samples (Fig. 8). The contrast around the dislocations is unusually thick. At the same moment the diffraction patterns show extra spots at the $1 / 3$ and $2 / 3$ of $\left\langle 110_{\mathrm{B} 2}\right\rangle$ reflections which means that the $\mathrm{R}$-phase is present in the sample. We were not able to directly localize the Rphase due to small distances between the R-phase and matrix spots. They are too small to separate the R-phase spot by the objective aperture and take the dark field image of the $\mathrm{R}$ phase only. However, the thick contrast seen around the dislocations allows us to suggest that these are the places where the R-phase starts to form. Therefore, we believe that the reason of two stages of the $\mathrm{R}$ phase and the following B19' transformations is similar as in case of the alloys containing precipitates i.e. it is caused by differences in the strain fields close to the dislocation cell boundaries and inside the cells.

\section{Discussion}

Basing on the obtained results there was created a theoretical model of the transformations occurring in the NiTi alloy containing coherent precipitates. Two phenomena have been taken into account: the heterogeneity of the strain fields as well as the chemical composition of the matrix.

Considering a simple parent phase $\Rightarrow$ martensite transformation the thermodynamical equilibrium between the two phases is given by the equation:

$$
\Delta G^{\mathrm{P}-\mathrm{M}}=\Delta H^{\mathrm{P}-\mathrm{M}}-T \Delta S^{\mathrm{P}-\mathrm{M}}+\Delta E_{\mathrm{e}}^{\mathrm{P}-\mathrm{M}}+\Delta E_{\mathrm{i}}^{\mathrm{P}-\mathrm{M}}=0
$$

where $\Delta E_{\mathrm{e}}^{\mathrm{P}-\mathrm{M}}$ is the change of the system elastic energy, $\Delta E_{\mathrm{i}}^{\mathrm{P}-\mathrm{M}}$ is the friction energy part connected with the transformation, and $\Delta H^{\mathrm{P}-\mathrm{M}}$ and $\Delta S^{\mathrm{P}-\mathrm{M}}$ are the changes of enthalpy and entropy, respectively. $T$ is temperature.

Then, the change of the elastic energy can be expressed as follows:

$$
\Delta E_{\mathrm{e}}^{\mathrm{P}-\mathrm{M}}=\sum_{i j}-\frac{1}{2} \sigma_{i j}^{t} \varepsilon_{i j}^{t}-\sigma_{i j} \varepsilon_{i j}^{t}-\sigma_{i j}^{d} \varepsilon_{i j}^{t}
$$



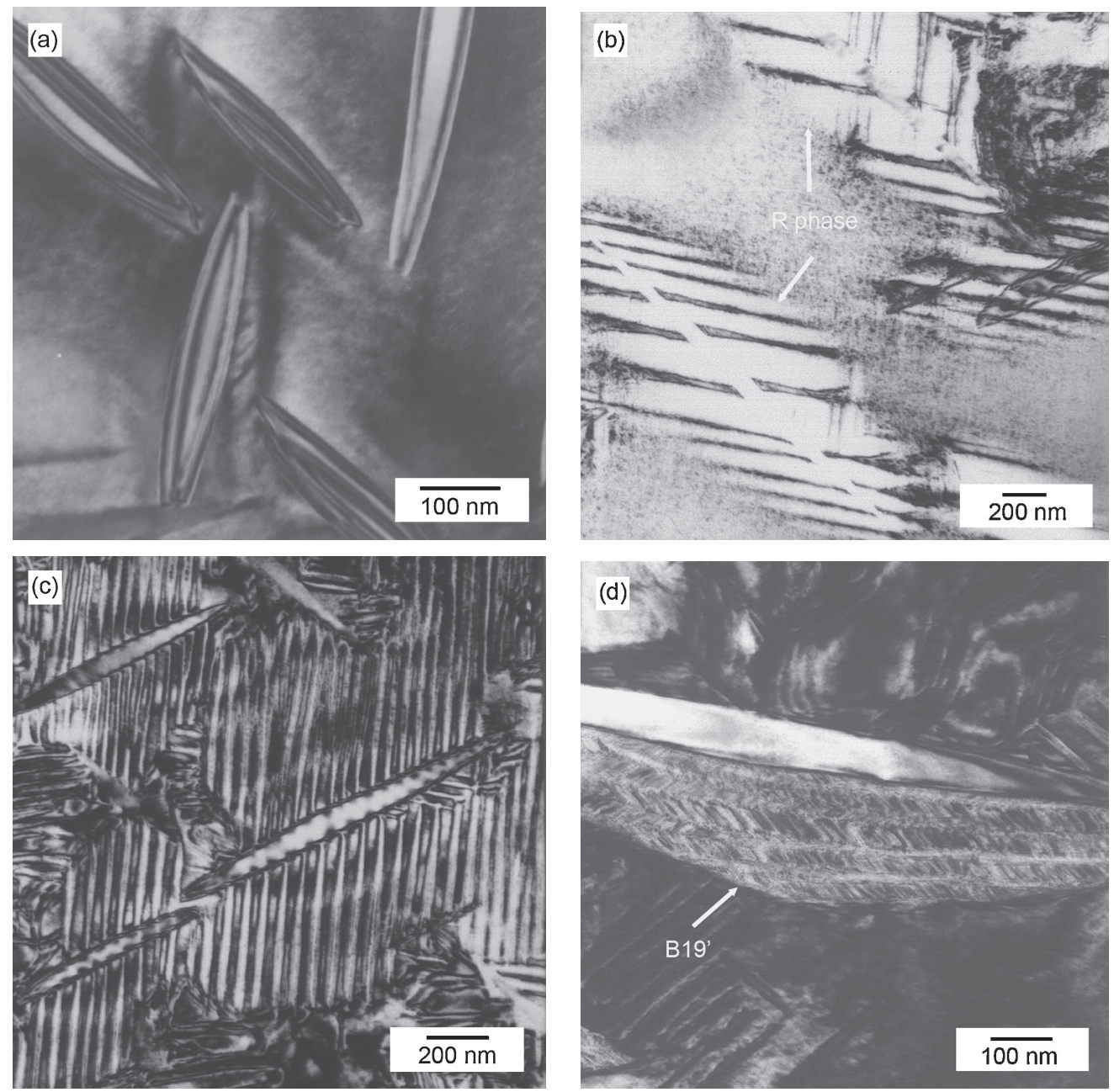

Fig. 6 Structure changes in the NiTi alloy during in situ cooling in the microscope, (a) at room temperature- $-\mathrm{Ni}_{4} \mathrm{Ti}_{3} \mathrm{particles}$ in the $\mathrm{B} 2$ phase matrix, (b) at about $280 \mathrm{~K}$-needles of the R-phase are visible around the particles, (c) at about $270 \mathrm{~K}$ - the whole B2 phase has transformed to the R-phase and (d) at about $170 \mathrm{~K}$ - first plates of the B19' martensite formed around the particles.

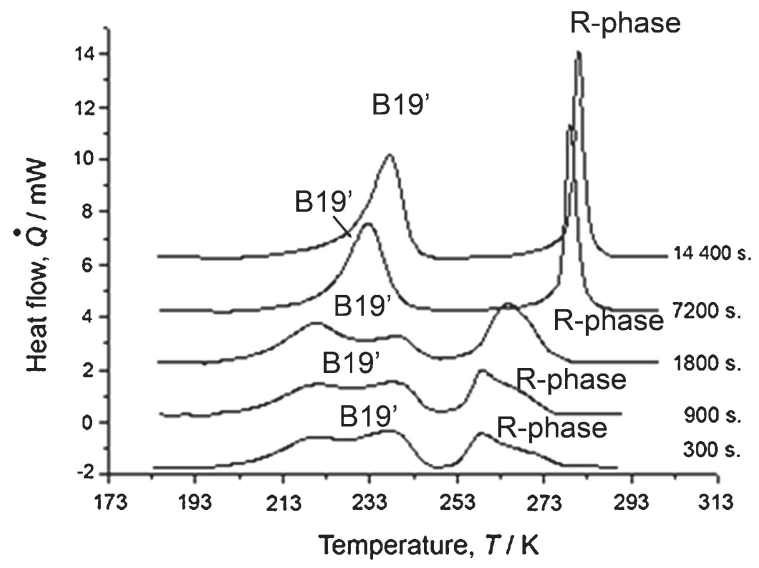

Fig. 7 DSC curves on cooling for the near-equiatomic alloy deformed by cold rolling by $10 \%$ and then annealed at $673 \mathrm{~K}$ for different times.

where $\sigma_{i j}, \sigma_{i j}^{d}, \sigma_{i j}^{t}$ are the external stress, internal stress caused by defects and the internal stress caused by the transformation itself, respectively. $\varepsilon_{i j}^{t}$ is the transformation strain. Assuming that for $T=M_{\mathrm{S}}$ (martensite start temperature) both the friction energy $\Delta E_{\mathrm{i}}^{\mathrm{P}-\mathrm{M}}$ and the transformation stress $\sigma_{i j}^{t}$ are so small that they can be neglected, the following expression can be obtained: ${ }^{8)}$

$$
M_{\mathrm{s}}=T_{0}+\frac{\Delta E_{\mathrm{e}}^{d}}{\Delta S^{\mathrm{P}-\mathrm{M}}}
$$

where $T_{0}=\Delta H^{\mathrm{P}-\mathrm{M}} / \Delta S^{\mathrm{P}-\mathrm{M}}$. Let's now consider a situation in which there exists non-homogeneous distribution of strain in the material and thus its whole volume can be divided into two parts $\mathrm{V}_{1}$ and $\mathrm{V}_{2}$ that differ in the strain stage so that $\sigma_{1}<\sigma_{2}$, where $\sigma_{1}$ and $\sigma_{2}$ are the mean values of stress in $\mathrm{V}_{1}$ and $\mathrm{V}_{2}$, respectively. This is a situation of an alloy containing coherent precipitates that produce strain fields in the matrix. Then the $\mathrm{V}_{1}$ will be a region far from the particles, while $\mathrm{V}_{2}-\mathrm{a}$ region around them. It can be calculated that the difference in the R-phase transformation temperature between those two regions is given by the expression:

$$
T_{2}^{\mathrm{PR}}-T_{1}^{\mathrm{PR}}=\frac{\left[E_{\mathrm{e}}^{\mathrm{R}}(2)-E_{\mathrm{e}}^{\mathrm{P}}(2)\right]-\left[E_{\mathrm{e}}^{\mathrm{R}}(1)-E_{\mathrm{e}}^{\mathrm{P}}(1)\right]}{\Delta S^{\mathrm{PR}}} .
$$

This can be rewritten:

$$
T_{2}^{\mathrm{PR}}-T_{1}^{\mathrm{PR}}=\frac{\left[E_{\mathrm{e}}^{\mathrm{P}}(1)-E_{\mathrm{e}}^{\mathrm{P}}(2)\right]-\left[E_{\mathrm{e}}^{\mathrm{R}}(1)-E_{\mathrm{e}}^{\mathrm{R}}(2)\right]}{\Delta S^{\mathrm{PR}}}
$$

where the superscript PR means the parent phase $\rightarrow$ R-phase transformation. Since $\Delta S^{\mathrm{PR}}$ is negative (the transformation is 

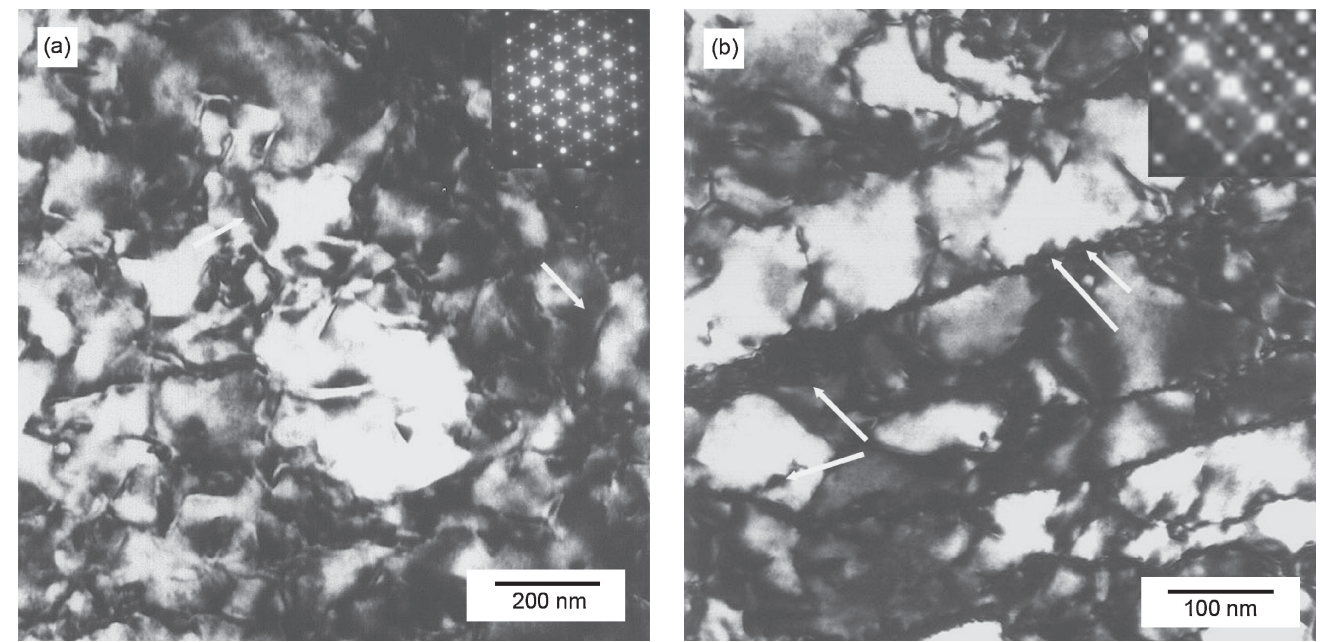

Fig. 8 Dislocation structure of the near-equiatomic alloy deformed by $10 \%$ and then annealed at $673 \mathrm{~K}$ (a) and $773 \mathrm{~K}$ (b) for $3.6 \mathrm{ks}$, the R-phase (its diffraction pattern shown in top right corners) formed at the dislocations causes thick dark contrast around them. Arrows show examples of the R-phase formed close to the dislocations.

(a)

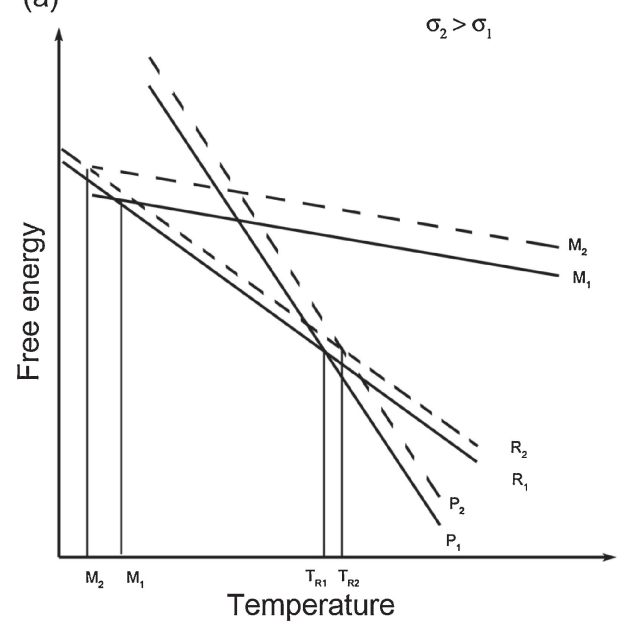

(b)

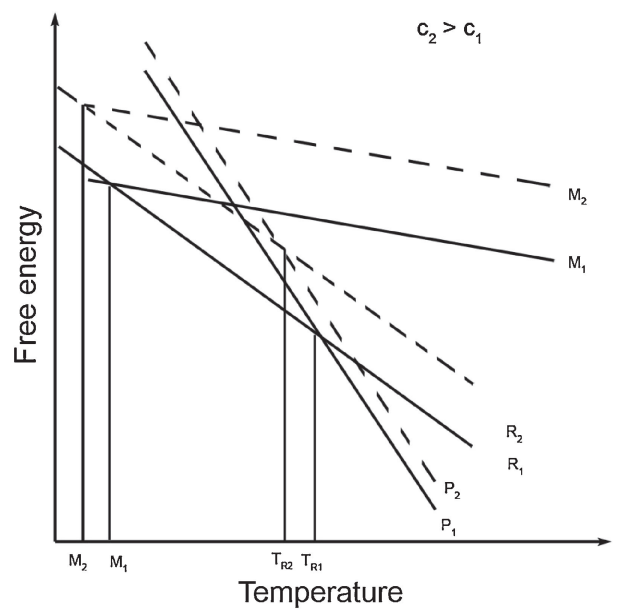

Fig. 9 Free energy of the P (parent phase), R (R-phase) and martensite M (B19' martensite) versus temperature for two regions of the sample that differ in internal stress (a) or Ni-concentration (b) and resulting changes of the characteristic temperatures.

exothermal and thus it occurs with the heat release), $E_{\mathrm{e}}^{\mathrm{P}}(2)>$ $E_{\mathrm{e}}^{\mathrm{P}}(1)$ and taking into account that the R-phase transformation leads to the smaller increase of elastic energy in the regions of strain fields ${ }^{9,10)}$ i.e. $E_{\mathrm{e}}^{\mathrm{R}}(1)-E_{\mathrm{e}}^{\mathrm{R}}(2)<E_{\mathrm{e}}^{\mathrm{P}}(1)-E_{\mathrm{e}}^{\mathrm{P}}(2)$, thus $T_{2}^{\mathrm{PR}}>T_{1}^{\mathrm{PR}}$. This means that in the region of higher stress the transformation occurs at higher temperature. Identical considerations can be carried out for the following $\mathrm{R}$ to B19' martensite transformation.

$$
\begin{aligned}
& T_{2}^{\mathrm{RM}}-T_{1}^{\mathrm{RM}}=\frac{\left[E_{\mathrm{e}}^{\mathrm{M}}(2)-E_{\mathrm{e}}^{\mathrm{R}}(2)\right]-\left[E_{\mathrm{e}}^{\mathrm{M}}(1)-E_{\mathrm{e}}^{\mathrm{R}}(1)\right]}{\Delta S^{\mathrm{RM}}} \\
& T_{2}^{\mathrm{RM}}-T_{1}^{\mathrm{RM}}=\frac{\left[E_{\mathrm{e}}^{\mathrm{R}}(1)-E_{\mathrm{e}}^{\mathrm{R}}(2)\right]-\left[E_{\mathrm{e}}^{\mathrm{M}}(1)-E_{\mathrm{e}}^{\mathrm{M}}(2)\right]}{\Delta S^{\mathrm{RM}}} .
\end{aligned}
$$

Also in this case $\Delta S^{\mathrm{RM}}<0$, so the sign of the $T_{2}^{\mathrm{RM}}-T_{1}^{\mathrm{RM}}$ will depend on the difference between the elastic energies of the two regions $V_{1}$ and $V_{2}$.

The difference between the elastic energy in $\mathrm{V}_{1}$ and $\mathrm{V}_{2}$ for the B2 parent phase is similar to this difference for the B19' martensite, because these phases have similar elastic modula. ${ }^{11)}$ The difference between the elastic energy in the two regions for the R-phase is smaller because of its smaller value of the elastic modulus. This influences the value of the differences between the transformation temperature for the two regions. It is much larger for the $R \Rightarrow M$ than for the $\mathrm{B} 2 \Rightarrow \mathrm{R}$ transformation. In other words occurrence of the internal stresses in the matrix effects strongly the B19' martensite transformation temperature and less the R-phase transition temperatures. This effect is a consequence of different slopes of the free energy curves for the particular phases (Fig. 9(a)).

Similar considerations can be done in the case when there exist fluctuations of the chemical composition of the matrix. Again for simplicity let's divide the specimen into two volumes $\mathrm{V}_{1}$ and $\mathrm{V}_{2}$ which differ in the nickel content so that $\mathrm{c}_{1}<\mathrm{c}_{2}$, where $\mathrm{c}_{1}$ and $\mathrm{c}_{2}$ are the $\mathrm{Ni}$ concentrations in $\mathrm{V}_{1}$ and $\mathrm{V}_{2}$. In this case we assume that there is no local changes of strain. Thus, the thermodynamical equilibrium will be influenced only by the chemical part of the free energy $G_{\text {ch }}=H-T S$. The thermodynamical equilibrium between the $\mathrm{B} 2$ and the $\mathrm{R}$ phases can be written as: 


$$
\begin{gathered}
H_{1}^{\mathrm{P}}-T_{1}^{\mathrm{PR}} S_{1}^{\mathrm{P}}=H_{1}^{\mathrm{R}}-T_{1}^{\mathrm{PR}} S_{1}^{\mathrm{R}} \text { for the } \mathrm{V}_{1} \text { region } \\
H_{2}^{\mathrm{P}}-T_{2}^{\mathrm{PR}} S_{2}^{\mathrm{P}}=H_{2}^{\mathrm{R}}-T_{2}^{\mathrm{PR}} S_{2}^{\mathrm{R}} \text { for the } \mathrm{V}_{2} \text { region, } \\
\text { hence: } T_{1}^{\mathrm{PR}}=\frac{\Delta H_{1}^{\mathrm{PR}}}{\Delta S_{1}^{\mathrm{PR}}} \text { and } T_{2}^{\mathrm{PR}}=\frac{\Delta H_{2}^{\mathrm{PR}}}{\Delta S_{2}^{\mathrm{PR}}} .
\end{gathered}
$$

This means that local temperature of the transformation is determined by both enthalpy and entropy differences that cause not only the shift of the free energy curve but also change its slope. However, it can be show that for the studied $\mathrm{Ni}$ concentration $\Delta S$ does not depend on the matrix nickel content and it influences only the enthalpy. So, we can assume that $\Delta S_{1}^{\mathrm{PR}}=\Delta S_{2}^{\mathrm{PR}}$ thus:

$$
T_{1}^{\mathrm{PR}}-T_{2}^{\mathrm{PR}}=\frac{\Delta H_{1}^{\mathrm{PR}}-\Delta H_{2}^{\mathrm{PR}}}{\Delta S^{\mathrm{PR}}}
$$

The same consideration can be carried out for the $\mathrm{R} \Rightarrow \mathrm{B} 19^{\prime}$. In both $\mathrm{P} \rightarrow \mathrm{R}$ and $\mathrm{R} \rightarrow \mathrm{B} 19^{\prime}$ transformations $\Delta S$ is negative and $\Delta H$ for the exothermal transformation is also negative. From experimental data ${ }^{7)}$ we know that transformation temperature decreases with the increasing $\mathrm{Ni}$ concentration in the matrix $\left(T_{2}^{\mathrm{RM}}<T_{1}^{\mathrm{RM}}\right)$ and so the following relation must be fulfilled: $\left|\Delta H_{2}^{\mathrm{RM}}\right|>\left|\Delta H_{1}^{\mathrm{RM}}\right|$. Moreover, it is known that the R-phase transformation temperature versus Ni-concentration behaves in the same way as the B19' transformation temperature. Hence, the enthalpy changes of the $\mathrm{B} 2, \mathrm{R}$ and $\mathrm{B} 19^{\prime}$ phases must be related in the following way: $\Delta H_{\mathrm{B} 2}<\Delta H_{\mathrm{R}}<\Delta H_{\mathrm{B} 19^{\prime}}$ (Fig. 9(b)). Only in this case we will get the experimentally observed relationship of the characteristic temperatures and the Ni concentration.

However, in reality both these cases can occur simultaneously. In fact in some cases they must occur simultaneously. The following situations are possible:

(1) Presence of regions $V_{1}$ and $V_{2}$ in which $c_{2}>c_{1}$ and $\sigma_{2}>\sigma_{1}$

(2) Presence of regions $\mathrm{V}_{1}$ and $\mathrm{V}_{2}$ in which $\mathrm{c}_{2}>\mathrm{c}_{1}$, but $\sigma_{2}<\sigma_{1}$.

The first situation is simple and it leads to further split of the both transformation peaks because the both factors cause the free energy curves move in the same direction.

But the second situation in which in the region $\mathrm{V}_{1}$ there are coherency strains i.e. $\sigma_{1}>\sigma_{2}$ and in the same moment in the region the $\mathrm{Ni}$-concentration is reduced $\mathrm{c}_{1}<\mathrm{c}_{2}$ is more complicated as both the factors shift the free energy corves in opposite directions. In this case the transformation course will depend on values of the strain and concentration nonhomogeneities. If they are known, the model allows to predict the transformation behavior.

However, some general tendencies can be drawn also without knowing these values. The differences of strains have much stronger influence on the peak splitting of the B19' phase than in case of the R-phase transition. Thus, in the result of acting of the two factors one can get the situation when the $\mathrm{B} 19^{\prime}$ transition in $\mathrm{V}_{2}$ region will occur at higher temperature than in $\mathrm{V}_{1}$. Such a change of the transformation behavior will never occur in the case of the R-phase because this transformation is less sensitive for stress fields and sensitive to the chemical composition change in the same way as the B19' transformation.

\section{Conclusions}

(1) Presence of the internal stresses around precipitates and/or close to dislocations is the cause of the multiplied R-phase and B19' martensite transformations.

(2) Two stages of the B19' martensite transformation have never been observed in alloys at which this transition was not preceded by the R-phase transformation. Occurrence of the R-phase transformation causes decrease of the driving force for the $\mathrm{B} 19^{\prime}$ transformation. In the result the local changes in the elastic energy strongly affect the transformation temperatures.

(3) A thermodynamical model of the multiplied martensitic transformation was suggested; the model allows us to predict the transformation sequences in the two-component Ni-Ti alloys. The model includes the effect of local inhomogeneities of internal stress or chemical composition as well as the effect of coexistence of both.

(4) The splitting of the $\mathrm{R}$ phase and $\mathrm{B} 19^{\prime}$ martensite transformations are predicted by the model. The inhomogeneities in chemical composition give similar split of the peaks of both transformations, while the stress inhomogeneities influence the $\mathrm{B} 19^{\prime}$ transition much stronger than the R-phase.

(5) The changes in chemical composition are caused by the precipitation process. Thus, they have the diffusion character and do not lead to the occurrence of wellseparated regions of different compositions in the sample. This may cause the broadening of the DSC peaks but not their splitting. Therefore, there must be coexistence of both the factors i.e. internal stress and chemical composition inhomogeneities to get splitting of the R-phase peak, while the behaviour of the B19' transformation will depend on the factor that dominates.

\section{REFERENCES}

1) M. Nishida, C. M. Wayman and T. Honma: Metall. Trans. 17A (1986) 1505 .

2) H. Morawiec, D. Stroz, T. Goryczka and D. Chrobak: Scr. Mater. 35 (1996) 485.

3) D. Chrobak, D. Stróż and H. Morawiec: Scr. Mater. 48 (2003) 485

4) T. Todoroki and H. Tamura: Trans. Japan Inst. Met. 28 (1987) 83-94.

5) D. Stroz, J. Kwarciak and H. Morawiec: J. Mater. Sci. 23 (1988) 4127.

6) J. S. Zhu and R. Gotthardt: Phys. Lett. A 132 (1988) 279.

7) D. Stroz: Oddziaływanie znieksztalcen sieciowych na przebieg przemiany martenzytycznej w stopach NiTi, ed. by University of Silesia, (Katowice, 2005).

8) L. Bataillard, J. E. Bidaux and R. Gotthardt: Phil. Mag. A 78 (1998) 327.

9) Y. Liu and P. G. McCormick: Mater. Trans. JIM 37 (1996) 691-696.

10) H. Morawiec, D. Stróż, T. Goryczka and D. Chrobak: Scr. Mater. 35 (1996) 485.

11) L. Bataillard and R. Gotthardt: J. de Physique IV 5 (1995) C8-647. 